Not to be cited without permission of the authors

\title{
ETHNIC MINORITY POLICE OFFICERS AND DISPROPORTIONALITY IN MISCONDUCT PROCEEDINGS ${ }^{1}$
}

\section{GRAHAM SMITH, HARRY HAGGER JOHNSON AND CHRIS ROBERTS*}

\begin{abstract}
Concern with perceptions of disproportionality on the grounds of ethnicity in internal police misconduct proceedings surfaced in England and Wales in the early 2000s. This article commences with a discussion of the meaning of disproportionality and two forms, numerical and procedural, are identified. A brief review of existing research is followed by presentation of research on the experiences of serving and former Greater Manchester Police ethnic minority officers of procedural disproportionality in misconduct proceedings. The article concludes with a discussion of the implications of the research for equality and diversity and attempts to create more representative police services.
\end{abstract}

Keywords: police misconduct; disproportionality; ethnicity; equality and diversity, representative policing

\section{Introduction}

Sir William Macpherson's (1999) Stephen Lawrence Inquiry Report represented a critical moment in modern policing history. The Inquiry found the police services of England and Wales to be institutionally racist and asserted that primary responsibility for tackling the problem rested with the police. Macpherson's findings were accepted by the government, and Home Secretary Jack Straw quickly drafted an Action Plan to implement his 70 recommendations (Home Office, 1999a). Three recommendations, 64-66, addressed the need to increase the representation of ethnic minority personnel at every level of the police, and the Home Secretary and police authorities were required to set 'targets for recruitment, progression and retention of minority ethnic staff' (Macpherson, 1999: Rec. 64).

Closely connected to ethnic minority employment targets, disproportionality in misconduct proceedings emerged as a problem after publication of the Stephen Lawrence Inquiry Report. Allegations began to surface in the early 2000s (Calvert-Smith, 2005; Ghaffur 2004; Morris 2004; Muir 2001), and the National Black Police Association (2009) singled out the perception that ethnic minority officers were disproportionately subjected to misconduct investigations as one of the most disturbing developments affecting minority personnel in the decade after Macpherson reported. The following year an Association of Chief Police Officers (ACPO, 2010) survey of 40 police services concluded, although small numbers were

\footnotetext{
${ }^{1}$ The authors wish to express their gratitude to We wish to thank Greater Manchester Police, West Midlands Police, British Transport Police, the Association of Chief Police Officers, Home Office, National Policing Improvement Agency (now the College of Policing), and the Independent Police Complaints Commission for their funding and assistance with the research, and Chief Constable Sir Peter Fahy and Detective Superintendent Paul Savill, GMP, Charles Crichlow, President of the National Black Police Association, and Policing \& Society's two anonymous reviewers for their comments on earlier drafts of this article. The usual caveat applies. * Graham Smith, Senior Lecturer in Regulation, ManReg: the Manchester Centre for Regulation and Governance, University of Manchester School of Law, Oxford Road, Manchester M13 9PL; Harry Hagger Johnson, ManReg: the Manchester Centre for Regulation and Governance; Chris Roberts, Professor of Biostatistics, Institute of Population Health, University of Manchester. Contacting author Graham Smith: +44(0)1612753592; graham.r.smith@ manchester.ac.uk.
} 
involved, that minority officers were over represented in internal misconduct and covert counter-corruption proceedings.

This article draws on research commissioned by Greater Manchester Police (GMP), West Midlands Police (WMP), British Transport Police (BTP) and other policing stakeholders (Smith et al, 2012). The research investigated internal misconduct proceedings involving officers and civilian staff in the three services, and we focus entirely on proceedings concerning sworn police officers below. ${ }^{2}$ The article is separated into three sections. Consideration is given in the first to various ways of accounting for disproportionality, and a brief review is given of existing research on the experiences of ethnic minority officers. This is followed by a presentation of the research on the experiences of serving and former GMP ethnic minority officers subjected to internal misconduct investigations. Finally, the implications of the research for equality and diversity, particularly in the related policy fields of recruitment and progression, and attempts to create a more representative police service, are discussed.

\section{Accounting for disproportionality}

What does disproportionality mean in a socio-legal context? The concept is most commonly used when referring to quantifiable differences between a given population and a sub-group, and much research on disproportionality has relied on statistical analysis of aggregate numbers and their constituent parts (Blank et al, 2004; Pratt and Cullen, 2005; Skiba et al, 2005). The Oxford English Dictionary defines disproportion as: 'Want of proportion in number, quantity, size, etc.; lack of symmetry or due relation of quantity or number between things or parts of the same thing; the condition of being out of proportion.' Disproportionality may also refer to inappropriate human behaviour that is unfair, to either an individual or an identifiable group, or is an ineffective means of achieving a declared objective. In policing discourse, much prominence has been given to questions surrounding disproportional use of the power to stop and search (Bowling and Philips, 2007; Medina Ariza, 2013; Waddington et al, 2004). In European human rights law the concept of proportionality has several meanings, and generally serves to permit acts which restrict rights defined in the European Convention on Human Rights on grounds that the restriction is necessary in a democratic society (Emmerson et al, 2012). Where the right to life or the prohibition of torture has been engaged following an incident involving an agent of the state, there is a procedural obligation to conduct an independent and effective investigation (Smith, 2004; 2010). In light of developments in human rights law, in its guidance to the police services of England and Wales the Independent Police Complaint Commission (2013: para 9.14) explains: 'Investigators should adopt a proportionate approach to any investigation in order to ensure that, in the public interest, investigative resources are focused and employed efficiently and fairly.' Factors that are relevant to the proportionality of an investigation include the seriousness of the matter under investigation and the likelihood that the evidence obtained will support criminal, misconduct or performance proceedings.

The importance of procedural propriety in the criminal justice system has also been established in a rapidly growing body of influential research examining the connections between perceptions of procedural justice and legitimacy in law enforcement (Jackson et al,

\footnotetext{
${ }^{2}$ Counter-corruption data involving officers and staff for the year 2010/11 were also analysed: see Hagger Johnson et al (2013).
} 
2012; Murphy et al, 2009; Tyler, 1988). Research on the experiences of security and law enforcement personnel has demonstrated the importance of procedural justice to officer acceptance of the legitimacy of police management and the advantages of self-regulation to effective police governance (de Angelis and Kupchik, 2009; Tyler et al, 2007). It is of particular significance to the current discussion that procedural justice research is predicated on the supposition that the way in which persons perceive they have been treated in encounters with officials contributes to the legitimacy of institutions to make regulatory interventions in people's lives. That is to say, the perceptions individuals have of their personal experiences of subjugation to authority are not limited in importance to providing an impression of reality: they are substantively meaningful.

Human rights law and procedural justice research add to the understanding of disproportionality by showing that its existence is not only a matter of numbers; it may also be evidenced on an individual basis, and perceptions based on experience count. Disproportionality has multiple meanings and identification of numerical disproportionality, after controlling for a range of variables, cannot alone explain why a disparity may exist. Numerical and procedural disproportionality need to be distinguished and complementary quantitative and qualitative research methods have much to offer in accounting for the differential treatment of a group of people, particularly if disproportionality is perceived to occur as a consequence of discrimination or bias.

\section{Review of research on the experiences of ethnic minority officers}

In his early research on race relations in police services, before Macpherson reported, Holdaway $(1991 ; 1996 ; 1997)$ found that racialised relationships were largely founded on mundane features of occupational culture, including, for example, stereotyping, loyalty and drinking alcohol, and ethnic minority officers responded by developing their own coping strategies. Somewhat surprisingly, given that Macpherson recommended a package of recruitment, progression and retention measures, the Stephen Lawrence Inquiry Report (Macpherson, 1999) made no reference to personal experiences ethnic minority officers may have had of racism within the police. ${ }^{3}$ This apparent oversight was partly addressed with publication of Home Office research on the representation of ethnic minority officers in police services, which found that institutional racism, as defined by Macpherson, 'played a part in defining the careers of ethnic minority officers' (Bland et al., 1999: 51). ${ }^{4}$ Stone and Tuffin (2000) researched the attitudes of members of ethnic minority communities towards the police. They attributed major importance to public perceptions of ethnic minority officer's experiences of racism within the police and the need for these concerns to be addressed if a career in the police were to become a more attractive proposition (see also Waters et al, 2007).

Since implementation of the Home Secretary's Action Plan (Home Office, 1999a) a body of research has been published on the experiences of ethnic minority officers. Cashmore (2001) observed a reluctance of ethnic minority officers to complain about the racist behaviour of

\footnotetext{
${ }^{3}$ Reference was made to evidence given by the Metropolitan Police Service Black Police Association in support of the existence of institutional racism (Macpherson, 1999: paras 6.11, 6.27 and 6.28).

${ }^{4}$ A recommendation to research 'reasons why ethnic minority officers are more likely than white officers to leave the service as a result of dismissal and resignation' (Bland et al., 1999: 52) appears not to have been acted upon; Cooper and Ingram (2004) researched police retention and found that there was a higher rate of resignations of ethnic minority officers compared to all officers.
} 
colleagues for fear that it may damage their career prospects or leave them isolated and marginalised. Another deterrent to complaining, he explained, was that ethnic minority officers did not wish to harm working relations which depended on officers being able to fully trust each other when faced with the prospect of danger. In a follow up paper, Cashmore (2002) discussed ethnic minority officers' scepticism of recruitment targets and diversity training (see also Rowe and Garland, 2003), which focussed on police community relations rather than internal relations between officers, ${ }^{5}$ as means of challenging racism. The first Black Police Association (BPA) was created in the Metropolitan Police Service in 1994 (Holdaway, 1996) and a national body (NBPA) was inaugurated with the support of the Home Office in 1999 (O'Neill and Holdaway, 2007); since then Holdaway and O'Neill have tracked the development of black and Asian police associations across England and Wales. With the Macpherson reform agenda in its infancy, the pair identified a convergence of interest between chief constables and BPAs (Holdaway and O'Neill, 2004), and took issue with Cashmore's (2002) more sceptical analysis (O’Neill and Holdaway, 2007). They argued that an institutional memory, founded on shared experiences of racism, bonded BPA members together into an effective campaigning body that worked alongside ACPO officers in pursuit of ethnic minority employment targets (Holdaway and O'Neill, 2006). As services fell further and further behind their ten year recruitment targets (Home Office, 1999b) ${ }^{6}$ Holdaway pointed to more discerning BPA activists, whom had grown accustomed to covert racism, and ethnic minority officers were increasingly interested in the morality underpinning the behaviour of white colleagues:

If ethnic minorities within constabularies are to trust their white colleagues, they require evidence of appropriate moral values as well as action. They wish to know securely that colleagues are morally sincere and that there is harmony between others' words, actions, and unstated moral principles. (Holdaway, 2010: 262)

He went on to argue that the understandings and experiences of ethnic minority officers of covert racism within the police, of which there are a range of perspectives, were demanding of management attention and uniquely qualified BPA's and other associations to assist services overcome the low level of trust and confidence in the police held by ethnic minority communities (ibid.; see also Phillips, 2005). More recently, Holdaway (2013) acknowledged the damage caused to planned equality and diversity reforms by resilient police occupational cultures (Loftus, 2008), before ethnic minority recruitment and promotion opportunities were effectively stalled following introduction of the Coalition government's austerity measures in 2011.

The limited published academic research that has specifically examined disproportionality in police discipline proceedings has focussed on analysis of US police departments' internal affairs statistical data. This research has been associated with complaints raised by ethnic minority officers that proceedings unfairly brought by internal affairs units damaged their

\footnotetext{
${ }^{5}$ Neglect of equality and diversity within police services was identified by HM Inspectorate of Constabulary (2003) in the Diversity Matters thematic report.

${ }^{6}$ Shortly before the 2009 deadline a gamut of national police targets were replaced with the overarching objective of increasing public confidence (Minister for Policing, 2008). In September 2012, Minister for Policing, Damien Green, disclosed that the Ministerial Ethnic Minority Advisory Group, established to oversee recruitment, progression and retention after removal of the targets, last met in December 2009: Hansard, 13 September 2012 Col. 358W (http://www.publications.parliament.uk/pa/cm201213/cmhansrd/cm120913/text/120913w0002.htm\#120913400 03677).
} 
career prospects at a time when police departments were engaged in recruitment drives (Rojek and Decker, 2009).

Analysing internal affairs' complaints data in a Southeastern police department, research by Lersch and Miezkowski (2000) was designed, not to test for bias, but to ascertain if there were similarities in the number and type of internally and publicly generated complaints. Analysis of internally raised complaints revealed significant over-representation of minority officers. In a police department comprising 18.4 percent non-Caucasian officers, 19.9 percent of public complaints, which was not significantly out of proportion, and 39.4 percent of internal complaints were against minority officers (ibid::61). Using statistical data provided by the Philadelphia Police Department, Hickman et al (2001) did seek to establish whether ethnicity influenced decision-making in formal disciplinary proceedings involving patrol officers, but they did not find that ethnicity had a significant effect. However, the research did not separate internally and publicly generated allegations and Hickman et al did not expressly examine if there was disproportionality in internally raised complaints.

Testing Blalock's (1967) influential thesis that an increase in representation of minority personnel in an organisation may be perceived by the majority population to threaten their economic and political status, Rojek and Decker (2009) posited it could be evidenced in the police by identifiable disparities in the treatment of minority officers in misconduct proceedings. Blalock argued that a majority population's influence over the minority diminished as the ratio of minority personnel approached 50 percent, and Rojek and Decker observed this could help account for why Hickman et al did not find disparity in the Philadelphia Police Department, where 47.3 percent of patrol officers were from an ethnic minority background. Rojek and Decker's research on a Midwestern police department's internal affairs' data sought to establish if officer ethnicity was significant at three stages in the processing of internally and publicly raised complaints: i) referral to internal affairs; ii) determination (i.e. whether substantiated); and iii) decision to sanction. In a police department comprising 35.6 percent minority officers, Rojek and Decker identified ethnicity as a significant factor in referrals of internal complaints. 58.1 percent of internal complaints were recorded against minority officers compared to 37 percent of publicly raised complaints, which was in proportion to the number of serving minority officers (ibid.: 399). This disproportionate over-representation of minority officers at the referral stage was not replicated in the determination and sanctioning stages, and Rojek and Decker's research findings were consistent with those of Lersch and Mieczkowski (2000).

Although delayed by several decades, there are parallels between attempts to improve police representativeness in the US, following the 1960s civil rights protests, and in England and Wales in the 2000s, in response to the Stephen Lawrence Inquiry. Until recently, examination of disproportionality in misconduct proceedings in England and Wales had been largely in the form of reviews by police (Ghaffur, 2004; Lowe, 2005) or, for public bodies with responsibilities for oversight of the police (Calvert-Smith 2005; Morris, 2004). Each of these reviews referred to the apparent preference of supervisors to refer the behaviour of ethnic minority officers to professional standards departments for formal investigation, whereas they would deal with white officers informally face-to-face, as a principal cause of perceptions of disproportionality. These concerns were further articulated in a number of reports that evaluated police progress on equality and diversity ten years after the Stephen Lawrence Inquiry Report (Bennetto, 2009; Home Affairs Committee, 2009; National Black Police Association, 2009). Using human resources and professional standards statistical data, Smith et al (2012) analysed internal misconduct proceedings in the GMP, WMP and BTP services 
between 1 April 2007 and 31 March 2011. Officer ethnicity was identified as significant in research on the internal misconduct investigations data of the WMP and BTP. In the WMP, 13.2 percent of internal misconduct investigations were against ethnic minority officers whom comprised 7.7 percent of the officer population. In the BTP, where ethnic minority officers comprised 6.9 percent of officers, 10.4 percent of internal misconduct investigations were against minority officers. Ethnicity was not significant for substantiations or the issue of sanctions in either service; findings that were consistent with Lersch and Mieczkowski (2000) and Rojek and Decker's (2009) research. For GMP, in contrast, numerical disproportionality was not identified in the misconduct statistical data. Lack of statistical power may explain why ethnicity was not significant: ${ }^{7}$ a total of 454 officers were investigated, of which only 25 were of an ethnic minority background. Only three investigations involving ethnic minority officers were substantiated, none of which resulted in the issue of sanctions, giving a substantiation rate of 12 percent. The substantiation rate of investigations involving white officers was 25.9 percent $(\mathrm{n}=111)$, and 28 officers were sanctioned (Hagger Johnson et al 2013).

\section{Procedural disproportionality and the experiences of ethnic minority officers}

Whereas the US research briefly reviewed above only analysed recorded complaints data and was limited to identification of numerical disproportionality, the GMP research also utilised qualitative methods, including documentary analysis and semi-structured interviews, in an effort to identify procedural disproportionality.

GMP's Black and Asian Police Association (BAPA) first raised the issue of disproportionality in misconduct proceedings in a spring 2003 meeting with the Chief Constable. The Chair of the Association claimed that ethnic minority officers were treated more harshly than white colleagues. Matters came to a head later that year when, in August, the BBC Asian Network (2003) interviewed GMP officers who were critical of the service's internal procedures for dealing with complaints of racism. In November, shortly after the showing of the BBC's (2003) The Secret Policeman spy on the wall documentary (McLaughlin, 2007), the Police Complaints Authority (predecessor of the Independent Police Complaints Commission) became involved. A senior officer of GMP's Internal Affairs Branch (IAB), precursor of the Professional Standards Branch (PSB) in 2006, complained that intervention by Command officers in misconduct proceedings resulted in minority officers being treated more leniently than white officers (Ward, 2003) (see further below).

A subsequent GMP review of publicly and internally raised complaints investigations between April 2002 and September 2004 identified a pattern of disproportionality (Lowe, 2005). However, ethnic minority officers invited to participate in the research declined to be interviewed and scepticism remained of GMP attempts to address dissatisfaction. The research on which this article is based was commissioned partly in response to continuing ethnic minority officer mistrust, and an interview sample was organised with the help of PSB personnel and minority staff association representatives. Eight former and serving ethnic minority officers, all male and of various ranks and length of service, who had been

\footnotetext{
${ }^{7}$ Further research on an alternative GMP data source, Investigation Officer reports, indicated that a supervisory officer or colleague was more likely to refer an ethnic minority officer than a white officer to the Professional Standards Branch for investigation (Smith et al, 2012). Ethnicity was found to be significant following analysis of the 2010/11 GMP counter-corruption intelligence data: an ethnic minority officer was more than twice as likely to be subjected to covert intelligence processes as a white colleague (Hagger Johnson et al, 2013).
} 
investigated between 1999 and 2010, were interviewed. ${ }^{8}$ Four of the officers' cases fell within the 2007/08 to 2010/11 timeframe, meaning that the snowballing sampling method resulted in interviews with 16 percent of the minority officers identified in the statistical analysis of internal proceedings (see above). Thirteen Command and serving or former PSB personnel, with management and investigation responsibilities (all of whom were white), and six staff association (including Police Federation, Police Superintendents' Association, BAPA and Muslim Police Association) representatives were also interviewed. Of the 10 ethnic minority officers interviewed in total, six stated that their background was African Caribbean and four said Asian.

Despite procedural differences in the way in which their misconduct cases had been processed, ${ }^{9}$ all of the investigated officers interviewed spoke of broadly similar experiences. All but one officer acknowledged that they had either, done something wrong of some description while on duty, or their behaviour had aroused suspicion that they had done something wrong. One senior minority officer subjected to a lengthy investigation that was not substantiated told us: 'All BME [black and minority ethnic] officers you talk to in GMP who have been investigated will tell you about a similar case to theirs involving a white officer who wasn't investigated.' A principal grievance of minority officers was that after admitting their behaviour had not reached the required standard they were referred to the IAB or PSB, whereas white officers, whom they believed had misbehaved, were not: ${ }^{10}$

Don't get me wrong, there was always a reason and some evidence there - but the way they proceeded against black officers was different to the way they proceeded against white officers.

There were several ways by which officers came to learn of cases similar to their own. When discussing their predicament with colleagues, staff association representative or solicitor, they would be reassured that they had nothing to fear: 'the guys I spoke to couldn't believe what had happened: they told me not to worry about it, that I'd get a bollocking for it and others had done much worse than me.' In one case an officer complained that a serious lapse by white officers, which was material to the commission of a criminal offence, was dealt with informally by a divisional supervisor whereas he was referred to the PSB for investigation for not dissimilar behaviour, and which did not have a significant operational impact.

Once referred to the IAB or PSB several officers felt that cases against them were pursued in order to justify the referral, and the proceedings amounted to unjust treatment and punishment.

\footnotetext{
${ }^{8}$ Despite attempts, with the assistance of GMP PSB and Police Federation representatives, to contact white officers that had been referred to PSB for investigation, the research concluded without interviewing white officers investigated for misconduct.

${ }^{9}$ There has been significant reform of police misconduct procedures in recent years: in April 1999 discipline regulations were replaced by efficiency and conduct proceedings (Smith, 2001); the Independent Police Complaints Commission commenced operations in April 2004 (Smith, 2006), and assumed responsibility for investigation of more serious complaints and oversight of police investigations; GMP's IAB was reorganised on the recommendation of HM Inspectorate of Constabulary (2006) and renamed the PSB; and, in December 2008, new regulations were again introduced in line with Lord Taylor's (2005) recommendations to devolve responsibility for professional standards (Home Office, 2008).

${ }^{10}$ Supervisors are not required to record informal discussions with an officer about work performance and, except in one case where independent evidence was available, it was not possible for the research to evidence officers' perceptions of procedural disproportionality.
} 
I held my hands up and accepted it fully. This became an issue for PSB. They were like a dog on a bone and dishonesty became the issue.

There was no sanction or any form of action against me after the hearing. The only things they found me guilty of were things I had admitted. That does not warrant an investigation lasting more than two years, a four day recorded hearing with counsel representing IAB, the panel and me. I estimate the cost ran into hundreds of thousands.

Evidence in support of the existence of procedural disproportionality in internal misconduct proceedings in GMP was compelling. Currently serving Command and senior PSB personnel concurred with ethnic minority officers about the higher frequency of referrals to PSB. Some accepted that the perception of disproportionality was widespread and pointed to the way in which 'allegations surface' as a priority. One officer was more open and expressed the view that there was a longstanding tendency among PSB personnel to stereotype black officers as troublemakers and Asian officers as dishonest. Currently serving PSB investigators were the one category of interviewee that did not accept there was disproportionality. However, in contradiction to this standpoint differential treatment was apparent in the suggestion that minority officers received a 'better quality' of service because investigators took more care to ensure investigations were thorough. Investigators attributed this greater diligence to the fact that there was closer scrutiny of cases involving minority officers, and an awareness that they may be accused of racism otherwise. One investigator commented: 'You really need to make sure all of the Is are dotted and Ts are crossed. It's the fear factor.'

Having accepted in the first instance that referral to PSB may have been justified on the facts, subsequent assessment of the way in which they had been unfairly treated in comparison to white colleagues led ethnic minority officers to conclude that they had not done anything wrong. This, in turn, caused them to consider other reasons why they had been subjected to misconduct proceedings. Length of service had an important bearing on the way in which officers rationalised their experiences. Those who had joined the police prior to the Stephen Lawrence Inquiry referred to the overt racism that existed in the 1980s and 1990s. We were told that referral to PSB by colleagues was rare, then: 'officers making complaints against each other was an alien concept. It was not acceptable in terms of the culture in the police service.'(cf Cashmore, 2001) Disproportionality in misconduct proceedings was not considered to be particularly problematic until the early 2000s when minority officers, particularly active members of BAPA, noticed a sea change. Officers complained that they were encouraged to report behaviour of colleagues they considered to be discriminatory or disrespectful, only to discover that they would then be investigated for misconduct after counter allegations were made by white officers:

After Lawrence a lot changed ... officers were very aware of what they were doing, what they could and couldn't say. I observed, at a time when BAPA had started to develop, a sort of backlash where inappropriate behaviour that was acceptable, and part of the culture, was being challenged. The spotlight then came down on minority officers and we saw a concerted effort to discredit certain individuals, and BAPA, by offering up examples of BME officers who behaved in the same way as those that we had previously criticised.

Some of the ethnic minority officers interviewed had joined GMP as part of the postMacpherson recruitment drive and they had different opinions about racism. One officer said he had no experience at all of racism in the police, whereas another explained that the unfair 
treatment he received was entirely due to race: 'I think this has all happened because I am a black officer saying something about what is predominantly a white organisation, although there are a few blacks in it.' The commonly held view of ethnic minority officers who spoke to us was that referral, and the risk thereof, to PSB for investigation served to 'keep them in their place'. There was a general awareness that colleagues had been dismissed from the service and transferred from specialist units after making complaints about white colleagues, which served as an effective deterrent to complaining. We were told a civilian staff member left GMP shortly after he complained that a white officer had assaulted a black youth, and following which he was reported for an unrelated irregularity at work. Much mention was made of the use of misconduct proceedings to disrupt the career development of minority officers. It was suggested that once officers reached the rank of inspector they were subjected to greater scrutiny by their immediate superiors - 'as if they needed to be taught a lesson'. According to one senior minority officer investigated:

I think it has something to do with professional jealousy or perceived threats. White officers believe BME officers get more than white officers, that they get more because they are BME. ... Subconsciously this affects their decision making.

Another officer explained that he completed a course for promotion shortly after he was referred for investigation by a divisional supervisor. The allegation against him was not substantiated but, several years later, he was aware that all of the other officers who had completed the course with him had been promoted, and two had been promoted twice, whereas referral to IAB had brought his career to a standstill.

When asked why they understood there to be widespread perceptions of disproportionality in GMP's misconduct proceedings, Command and PSB personnel made frequent references to the 'police family' and the importance of loyalty: 'You have your family at home but when you come to work you have your police family; it's always been that way'. It is interesting to note that none of the ethnic minority officers interviewed, some of whom had senior management responsibilities, referred to the police family in this context. Senior white officers, however, attached major significance to the risk officers from different cultural backgrounds, particularly Asian, posed to the integrity of the police family. One PSB officer appeared to suggest that Asian officers represented an inherent risk to law enforcement:

With Asian culture, there are conflicts with the police code of conduct. There's a high expectation of loyalty in the police, this doesn't leave room for loyalties outside of the service or outside the law. Instinctively there is a greater sense of loyalty [to community] with Asian officers, a powerful pull in different directions that are in conflict. They have loyalties to different things at the same time.

For Asian officers this outlook created major difficulties and they expressed concern that their culture, including close family ties, living with parents despite earning enough to purchase their own home and accepting the authority of the male head of the family, created problems for the police. Rather than taking the time to understand colleagues with a different culture and different ways of doing things, officers complained that the standard approach in GMP was 'to believe it is wrong to be different'. An area where this reluctance to consider different cultural traditions created particular difficulties was in regard to the custom of lending money interest free. We were told of several cases where ethnic minority officers had been unfairly suspected of committing criminal offences simply because they had withdrawn large amounts of money from their bank accounts to lend to family or friends. 
When discussing the importance of ethnicity as grounds for the way in which they had been unfairly treated, minority officers explained that they did not believe this was the only reason why they had been investigated. Reference was made to the use of ethnicity in 'box ticking' exercises and an over-riding concern to give the impression that GMP was closer to achieving equality and diversity targets than was actually the case. According to minority officers, greater importance attached to cultural difference, which may be due to ethnic background, rather than ethnicity itself. According to one officer, for example:
Muslim officers are more different than other BME officers. The way they are socialised and the way they socialise, they don't drink for example and drink is important to police culture,.. It is intangible; you cannot put your finger on what it is. Some white officers are also treated like this; they are also different and think differently. It's deeper than religion and more to do with a culture which is more closed and traditional. The police have got to understand how these cultures work and how individuals project themselves in the police.

Cultural difference and the way in which GMP failed to appreciate its importance came up time and again in interviews with ethnic minority officers and staff association representatives.

I don't think we have reached a point where black and Asian officers have been catered for or feel able to invest in the force culture. If a BME officer is dismissed they are not seen to have taken the force down with them. They are seen as a fifth column, something external to the force... GMP thinks more about its image when it concerns white officers involved in corruption. A white officer can show his badge and get into a nightclub and a black officer cannot. An officer tried to do it once, and they were on the phone to report him straight away. You're not a Bobby if you're black or Asian.

A picture of a flawed approach to dealing with difference emerged in research interviews with GMP personnel. An interview conducted in the morning with a white senior officer describing how everybody had a drink and got on well together at a social event, was followed by an afternoon interview with a Muslim officer explaining that attitudes to alcohol were part of the problem (cf Holdaway, 1997). It was evident that senior managers were committed to reform, and equality and diversity initiatives under the Macpherson agenda and in response to The Secret Policeman had been introduced. It was equally apparent that they had not worked and appeared to have been abandoned altogether. ${ }^{11}$ The image interviewees painted was of haphazard and ineffective attempts to deal with cultural differences where top down messages collided with bottom up cultural norms (cf Loftus, 2008).

In their appraisals of professional standards, ethnic minority staff association representatives accepted their colleagues may have misbehaved or under-performed and that supervisory or management intervention may have been appropriate. What they took exception to was the common practice of singling out minority officers for remedial action and, more generally, denial of the right to express themselves culturally in ways which they believed would contribute to the development of GMP as a representative public service (cf Holdaway, 2010; Phillips, 2005). These views were shared in large part by Command officers, and one officer expressed their frustration at the service's failure to make progress in this 'bit of a minefield'. Whereas minority officers and staff association representatives understood disparate

\footnotetext{
${ }^{11}$ Specialist equality and diversity training provision in GMP was withdrawn in 2011 as part of a savings package to meet government imposed austerity targets (Gentleman, 2011).
} 
treatment in terms of racism, whether as overt, institutional, covert or subtle processes which discriminated against and disadvantaged minority officers, Command and PSB personnel, in contrast, pointed to the fear of being criticised as the primary cause.

\section{Discussion and conclusion}

The experiences of ethnic minority officers in GMP generally conform to the research and policy review findings presented above. Allegations of racial discrimination and disproportionality have been associated with several areas of police employment practice since publication of the Stephen Lawrence Inquiry Report: in addition to misconduct proceedings, attention has focussed on ethnic minority recruitment and progression. In the late 2000s GMP referred to the over-representation of ethnic minority officers in internally raised misconduct proceedings in diversity monitoring reports (GMP, 2009; Greater Manchester Police Authority, 2008; Lowe, 2010). However, research on GMP 2007/08 2010/11 statistical data did not reveal ethnicity to be significant (Hagger Johnson et al, 2013) and, given that only 25 ethnic minority officers were investigated and none were formally sanctioned, it is difficult to understand why there was a perception of numerical disproportionality. Qualitative research, which drew on documentary analysis and semistructured interviews with GMP personnel, identified procedural disproportionality in a timeframe dating back to the late 1990s. The evidence pointed to a readiness across the service to subject ethnic minority officers to formal proceedings, whereas the tendency was to rely on informal measures when addressing similar concerns with the behaviour of white officers.

Five signal cases were identified in the research; three in 2003, one in 2005 and one in 2010. Each of these cases attracted media attention and were often mentioned by officers in interviews. Importance attaches to the three 2003 cases because they were live when a dispute flared up between BAPA and a senior PSB officer, with claims and counter-claims that ethnic minority officers were treated more harshly or more leniently than white officers (see above). That historic cases should remain fresh in the minds of officers nearly ten years later, reinforced by reference to more recent cases, confirms the importance of institutional memory (Holdaway and O'Neill, 2006) to the enduring grievances of black and Asian officers and indicates that GMP have struggled to move on since 2003. Signal cases inform debate and, in turn, affect policy and practice (Innes, 2004). They also help understand the current condition of professional standards practice and the relatively small number of misconduct proceedings and low substantiation rates recorded in GMP between 2007/08 and 2010/11. It is suggested that far reaching concerns and unresolved conflicts dating back at least to 2003, which was also the year The Secret Policeman was broadcast, have contaminated professional standards practice across GMP and help explain the apparent paralysis in misconduct proceedings.

Although there was a broad consensus among ethnic minority officers, Command and PSB managers about the existence of procedural disproportionality, there was a gulf between them in their understanding of the cause. Ethnic minority staff association representatives were critical of managers for what they perceived to be reluctance to challenge discrimination and prejudice. This was based on their assessment that managers were too willing to accept claims that ethnic minority officers were treated differently because of a purported fear among white supervisors and misconduct investigators of being accused of racism. An experiential shift is apparent in relations between GMP Command, PSB and BAPA over the 
course of less than a decade. Whereas PSB managers were critical of interventions by Command officers on behalf of ethnic minority officers in 2003, in 2012 ethnic minority staff association representatives were critical of Command officers for what they perceived to be abnegation of leadership, as displayed by their unwillingness to address outstanding grievances associated with misconduct proceedings.

The point of contention here may be put straightforwardly as follows: is differential treatment of ethnic minority officers, adherence to formal misconduct procedures in preference to reliance on informal measures, due to fear of being criticised for racism or racial bias? Misconduct investigators were not only worried about what ethnic minority colleagues may accuse them of, they were also concerned that line managers took a greater interest in cases involving ethnic minority officers and their decisions were more likely to be scrutinised. It is evident that moral values play an important part in both defining misbehaviour and the proportionality of responses to it. This resonates with Holdaway's (2010) thesis on the unique competence of ethnic minority officers to identify and comprehend racism and the need for managers to take into account a range of experiences. It is suggested that engagement between proponents of disputed racialised accounts for behaviour that damages trust and confidence within GMP is a pressing issue. Not only for the purpose of addressing internal divisions, but also in the interest of creating a representative police service which enjoys the trust and confidence of ethnic minority communities. This issue is therefore an institutional rather than individual one and is rooted in GMP's flawed approach to dealing with difference.

Ethnic minority officers who had been subjected to misconduct investigations told of a range of emotions and anxieties they experienced including hurt, anger, isolation, insecurity, mistrust, vulnerability and injustice. At the end of one interview an officer volunteered that he had not been able to speak openly and honestly about his ordeal to colleagues, family or friends, and he said that participation in the research had been a cathartic experience. These officers' experiences bear a close resemblance to those recounted by members of the public who have complained against the police or pursued claims for damages in the civil courts (Ransley et al, 2007; Smith, 2003; Waters and Brown, 2000). Media portrayals of the injustices experienced by complainants, whether police officers or citizens, and particularly if successful in civil or employment tribunal proceedings following an unsympathetic response to a complaint, have a major influence on police community relations. At a time when GMP was attempting to build a diverse and representative public service, the five signal misconduct cases, and several others that attracted media attention, have communicated negative messages to Greater Manchester's multi-cultural communities about the status of serving ethnic minority officers. Attitudinal research in ethnic minority communities has shown that experiences of ethnic minority police within police services have an adverse impact on the attractiveness of a police career (Stone and Tuffin, 2000; Waters et al, 2007).

GMP failed to achieve the ethnic minority recruitment target of 7 percent set by the Home Office as part of the Macpherson agenda (1999b). Starting from the 1999 baseline of 2.4 percent $(\mathrm{n}=166)$, annual statistics published by the Home Office (see, for example, Clegg and Kirwan, 2006; Dhani, 2012; Povey and Nguyen, 2001) reveal that progress was slow until 2010 (Sigurdsson and Dhani, 2010), and since then the proportion of serving ethnic minority officers stalled at 4.6 percent before rising to 4.8 percent in 2013 (Home Office, 2013). The percentage of ethnic minority officers serving in GMP, the third largest police service in England and Wales, compares unfavourably with the proportion serving in the largest, the Metropolitan Police Service, 10.5 percent, and second largest, West Midlands Police, 8.3 percent, and is below the national average of 5.1 percent (see Table I.). 
Table I. Police officers by ethnicity and rank, as at 31 March 2013

\begin{tabular}{|c|c|c|c|c|c|c|c|c|c|c|c|c|}
\hline \multirow{2}{*}{ 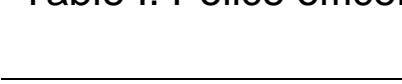 } & \multicolumn{3}{|c|}{ Total ranks } & \multicolumn{3}{|c|}{ Constables } & \multicolumn{3}{|c|}{ Sergeants, inspectors and chief inspectors } & \multicolumn{3}{|c|}{ Superintendents and above } \\
\hline & Total & BME & (\% of total) & Total & BME & (\% of total) & Total & BME & (\% of total) & Total & BME & (\% of total) \\
\hline Greater Manchester Police & 7202 & 343 & $(4.8)$ & 5069 & 271 & $(5.3)$ & 1510 & 77 & $(5.1)$ & 82 & 4 & (4.9) \\
\hline West Midlands Police & 7615 & 629 & (8.3) & 6084 & 515 & $(8.5)$ & 1465 & 109 & $(7.4)$ & 66 & 5 & (7.6) \\
\hline Metropolitan Police Service & 30398 & 3186 & (10.5) & 23283 & 2777 & (11.9) & 6856 & 390 & (5.7) & 236 & 18 & (8.0) \\
\hline England and Wales & 132608 & 6755 & (5.1) & 101720 & 5592 & (5.8) & 29408 & 1111 & (3.8) & 1480 & 52 & (3.5) \\
\hline
\end{tabular}


Potential recruits are also mindful of the career development opportunities that would be available to them if they were to join the police (Stone and Tuffin, 2000; Waters et al, 2007). With half of the ethnic minority officers interviewed complaining that their promotion prospects had been damaged as a consequence of investigation by PSB, the GMP research indicated a connection between disproportionality in misconduct proceedings and progression. Home Office ethnicity and rank figures presented in Table I. show that a smaller proportion of ethnic minority officers serve in the supervisory and senior management ranks in GMP compared to the other two largest police services, although the percentage is higher than the national average.

Research has shown that ethnicity is significant in misconduct proceedings in West Midlands Police (see above) and the Metropolitan Police Service (Morris, 2004). These two services have also fallen behind with their ethnic minority recruitment programmes, and minority officers are under-represented in all ranks. Although the GMP qualitative research disclosed local factors had an important effect, it is held that the procedural disproportionality findings are generalizable. The GMP research supported the conclusion that disproportionality in misconduct proceedings, poor recruitment and under-representation of ethnic minority officers in the promoted ranks are symptomatic of a flawed approach to dealing with difference. The evidence did not indicate that managers failed to introduce equality and diversity initiatives, more apparent was the institutional reluctance to pursue them and overcome the inevitable obstacles to progress. In place of a clear and resolute strategy to promote understanding and tolerance there appears to have been tacit acceptance that cultural differences, particularly with regard to ethnicity, were irreconcilable. To protect against reigniting unresolved disputes the tendency in GMP prior to the commissioning of the research on which this article is based was to avoid discussion of sensitive issues, which resulted in the emergence of an overpoweringly pessimistic equality and diversity narrative.

GMP took the national lead on disproportionality in misconduct proceedings shortly after the Home Office (2009) rejected a recommendation of the Equality and Human Rights Commission (Bennetto, 2009) to commission research on the subject. Inevitably, by opening the service up to independent examination, GMP's equality and diversity practices have attracted criticism (Brown, 2012; Qureshi, 2012), and the openness and transparency generated by the research has been maintained following publication of the findings online (Smith et al, 2012). GMP achieved this externally by organising a practitioner conference in the spring of 2013, in collaboration with the NBPA and University of Manchester, which examined disproportionality in misconduct proceedings in the police, medical and legal professions (Ellen et al, 2013). Internally, a working group is currently exploring how to improve GMP's dealing with difference strategy, including discussion of how to address historical misconduct cases. It is suggested that further independent scrutiny will be needed to understand the extent to which GMP's initiatives, and those introduced by other police services, have a demonstrable impact on policy and practice.

\section{References}

Association of Chief Police Officers (2010), Implementation of the New Misconduct Arrangements: Impact upon Officers from Minority Ethnic Groups. Association of Chief Police Officers (unpublished). 
Bennetto, J. (2009), Police and racism: What has been achieved 10 years after the Stephen Lawrence Inquiry report? Equality and Human Rights Commission.

Blalock, H. M., Jr. (1967). Toward a theory of minority-group relations. Wiley.

Bland, N., Mundy, G., Russell, J. and Tuffin, R. (1999), Career Progression of Ethnic Minority Officers, Police Research Series Paper 107. Home Office Policing and Reducing Crime Unit, Research, Development and Statistics Directorate.

Blank, R. M., Dabady, M., and Citro, C. F. (eds) (2004) Measuring Racial Discrimination. National Academies Press.

Bowling, B. and Phillips, C. (2007), 'Disproportionate and Discriminatory: Reviewing the Evidence on Police Stop and Search', Modern Law Review, 70/6: 936-961.

Brown, J. (2012), 'Black and Asian officers more likely to face police enquiries', The Independent, 25 September.

BBC (2003), 'Anger after police racism film'. http://news.bbc.co.uk/1/hi/uk/3212442.stm (accessed 28 November 2013).

BBC Asian Network (2003), 'Asian officers criticise force'. http://news.bbc.co.uk/1/hi/england/manchester/3054417.stm (accessed 28 November 2013).

Calvert-Smith, D. (2005), The Police Service in England and Wales: Final report of a formal investigation by the Commission for Racial Equality. Commission for Racial Equality.

Cashmore, E. (2001), 'The experiences of ethnic minority police officers in Britain: underrecruitment and racial profiling in a performance culture', Ethnic and racial studies, 24/4: 642-659.

Cashmore, E. (2002), 'Behind the window dressing: ethnic minority police perspectives on cultural diversity', Journal of Ethnic and Migration Studies, 28/2: 327-341.

Clegg, M. and Kirwan, S. (2006), Police Service Strength: England and Wales, 31 March 2006. Home Office.

Cooper, C. and Ingram, S. (2004). Retention of police officers: a study of resignations and transfers in ten forces, Occasional Paper No. 86. Home Office Research, Development and Statistics Directorate.

De Angelis, J. and Kupchik, A. (2009), 'Ethnicity, trust, and acceptance of authority among police officers', Journal of Criminal Justice 37/3: 273-279.

Dhani, A. (2012), Police Service Strength: England and Wales, 31 March 2012. Home Office.

Ellen, D., Fegan, T., Hassell, K., Munk, T., Schafheutle, Seston, L. and Smith, G. (2013), Disproportionality in the Professions: Working together to understand and respond to discrimination and prejudice in the workplace. ManReg Working Paper:

https://www.escholar.manchester.ac.uk/api/datastream?publicationPid=uk-ac-manscw:213964\&datastreamId=FULL-TEXT.PDF (accessed 28 November 2013).

Emmerson, B., Ashworth, A. and Macdonald, A. (2012), Human Rights and Criminal Justice, Third edition. Sweet \& Maxwell.

Gentleman, A. (2011), 'Police force's colour-coded redundancy letters give staff the blues', The Guardian, 11 January.

Ghaffur, T. (2004), Thematic review of race and diversity in the Metropolitan Police Service. Metropolitan Police Service.

GMP (2009), Diversity Monitoring 2008/09. GMP: http://www.gmp.police.uk/content/WebAttachments/D3887AF776F85D3080257A160031 DFE5/\$File/Diversity\%20Monitoring\%202008-09\%20website.pdf (accessed 28 November 2013). 
GMP (2013), Equality Duty Breakdown: Officer (March 2013). GMP: http://www.gmp.police.uk/content/WebsitePages/6795A1DF28C9BF0F80257A160029F0 9A? OpenDocument (accessed 28 November 2013).

Greater Manchester Police Authority (2008), Report of the Chief Constable to the Police Authority $14^{\text {th }}$ November 2008: Diversity Monitoring Data - 2007/08. GMPA (copy of Report in the possession of the Contacting Author).

HM Inspectorate of Constabulary (2003), Diversity Matters. Home Office Communication Directorate.

HM Inspectorate of Constabulary (2006), Inspection of Greater Manchester Police Professional Standards. HM Inspectorate of Constabulary.

Hagger Johnson, H., Smith, G. and Roberts, C. (2013), 'Disproportionality in internal misconduct and counter-corruption proceedings in three English police services', Policing: A Journal of Policy and Practice, 7/4: 359-369.

Hickman, M. J., Lawton, B. A., Piquero, A. R., \& Greene, J. R. (2001), 'Does race influence police disciplinary process?', Justice Research and Policy, 3/1: 97-113.

Holdaway, S. (1991), 'Race relations and police recruitment', British Journal of Criminology, 31/4: 365-382.

Holdaway, S. (1996), The Racialisation of British Policing. Macmillan.

Holdaway, S. (1997), 'Constructing and sustaining 'race' within the police workforce', British Journal of Sociology, 19-34.

Holdaway, S. (2010), 'Understanding 'trust' and 'confidence': Problems within and out with constabularies', Policing, 4/3: 258-264.

Holdaway, S. (2013), 'Police race relations in the Big Society: Continuity and change', Criminology and Criminal Justice, 13/2: 215-230.

Holdaway, S. and O'Neill, M. (2004), 'The Development of Black Police Associations Changing Articulations of Race within the Police', British Journal of Criminology, 44/6: 854-865.

Holdaway, S. and O'Neill, M. (2006), 'Institutional racism after Macpherson: an analysis of police views', Policing \& Society, 16/4: 349-369.

Home Affairs Committee (2009), 'The Macpherson Report - Ten Years On' Twelfth Report of Session 2008/09. The Stationery Office.

Home Office (1999a), Stephen Lawrence Inquiry: Home Secretary's Action Plan. Home Office.

Home Office (1999b), Race Equality - The Home Secretary's Employment Targets: Staff Targets of the Home Office, the Prison, the Police, the Fire and the Probation Services. Home Office.

Home Office (2009), Stephen Lawrence Inquiry 10 Years On Government Response. Home Office.

Home Office (2008), Home Office Guidance: Police Officer Misconduct, Unsatisfactory Performance and Attendance Management Procedures. Home Office.

Home Office (2013), Police workforce, England and Wales, 31 March 2013. https://www.gov.uk/government/publications/police-workforce-england-and-wales-31march-2013/police-workforce-england-and-wales-31-march-2013 (accessed 28 November 2013).

Independent Police Complaints Commission (2013), Statutory Guidance to the police service on the handling of complaints. Independent Police Complaints Commission.

Innes, M. (2004), 'Signal crimes and signal disorders: notes on deviance as communicative action', British Journal of Sociology, 55/3: 335-355. 
Jackson, J., Bradford, B., Hough, M., Hyhill, A., Quinton, P. and Tyler, T. R. (2012), 'Why do People Comply with the Law? Legitimacy and the Influence of Legal Institutions', British Journal of Criminology, 52/6: 1051-1071.

Laville, S. (2013), 'Call for new law to force police to tackle diversity crisis at top', The Guardian, 27 January.

Lersch, K. M., \& Mieczkowski, T. (2000), 'An examination of the convergence and divergence of internal and external allegations of misconduct filed against police officers', Policing: An International Journal of Police Strategies and Management, 23/1: 54-68.

Loftus, B. (2008), 'Dominant Culture Interrupted Recognition, Resentment and the Politics of Change in an English Police Force', British Journal of Criminology, 48/6: 756-777.

Lowe, J. (2005), GMP Internal Affairs Branch Discipline and Policy Unit Research Report. Greater Manchester Police (unpublished).

Lowe, J. (2010), 'Disproportionality in Professional Standards': presentation to Association of Chief Police Officers Professional Standards Conference.

http://www.acpoprostandardsconference.co.uk/2010-pres/Disproportionality.pdf (accessed 24 July 2013).

Medina Ariza, J. J. (2013), 'Police-initiated contacts: young people, ethnicity, and the 'usual suspects', Policing and Society, (ahead-of-print), 1-16.

Minister for Policing (2008), Policing Minister's Assessment of Minority Ethnic Recruitment, Retention and Progression in the Police Service: A Paper for the Home Secretary. Home Office.

Morris, W. (2004), The Case for Change: People in the Metropolitan Police Service. Morris Inquiry.

Muir, R. D. (2001), The Virdi Inquiry Report. Metropolitan Police Authority.

Murphy, K., Tyler, T. R. and Curtis, A. (2009), 'Nurturing regulatory compliance: Is procedural justice effective when people question the legitimacy of the law?', Regulation \& Governance 3/1: 1-26.

Macpherson, W. (1999), The Stephen Lawrence Inquiry. Home Office.

McLaughlin, E. (2007), The New Policing. Sage.

National Black Police Association (2009), The Post Stephen Lawrence Decade. National Black Police Association.

O'Neill, M. and Holdaway, S. (2007), 'Examining 'window dressing': The views of black police associations on recruitment and training', Journal of Ethnic and Migration Studies, 33/3: 483-500.

Phillips, C. (2005), 'Facing inwards and outwards? Institutional racism, race equality and the role of Black and Asian professional associations', Criminal Justice, 5/4: 357-377.

Povey, D. and Nguyen, T. C. (2001), Police Service Strength: England and Wales, 31 March 2001. Home Office.

Pratt, T. C. and Cullen, F. T. (2005), 'Assessing Macro-Level Predictors and Theories of Crime: A Meta-Analysis’, Crime and Justice, 32: 373-450.

Qureshi, Y. (2012), 'Greater Manchester Police's Asian officers "three times more likely to face corruption probe", says study', Manchester Evening News, 25 September.

Ransley, J., Anderson, J., and Prenzler, T. (2007), 'Civil litigation against police in Australia: Exploring its extent, nature and implications for accountability', Australian \& New Zealand Journal of Criminology, 40/2: 143-160.

Rojek, J. and Decker, S. H. (2009), 'Examining Racial Disparity in the Police Discipline Process', Police Quarterly, 12/4: 388-407.

Rowe, M. and Garland, J. (2003), 'Have you Been Diversified Yet?" Developments in Police Community and Race Relations Training in England and Wales', Policing and Society, 13/4: 399-411. 
Sigurdsson, J. and Dhani, A. (2010), Police Service Strength: England and Wales, 31 March 2010. Home Office.

Skiba, R. J., Poloni-Staudinger, L., Simmons, A. B. Feggins-Azziz, L. R. and Chung, C-G (2005), 'Unproven Links Can Poverty Explain Ethnic Disproportionality in Special Education?', Journal of Special Education, 39/3: 130-144.

Smith, G. (2001), 'Police Complaints and Criminal Prosecutions', Modern Law Review, 64/3: 372-392.

Smith, G. (2003), 'Actions for damages against the police and the attitudes of claimants', Policing and Society, 13/4: 413-422.

Smith, G. (2004), 'Rethinking Police Complaints', British Journal of Criminology, 44/1: 1533.

Smith, G. (2006), 'A Most Enduring Problem: Police Complaints Reform in England and Wales', Journal of Social Policy, 35/1: 121-141.

Smith, G. (2010), 'Every Complaint Matters: Human Rights Commissioner's Opinion concerning independent and effective determination of complaints against the police', International Journal of Law, Crime and Justice 38/2: 59-74.

Smith, G., Hagger Johnson, H., and Roberts, C. (2012), Disproportionality in Police Professional Standards. Greater Manchester Police. https://www.escholar.manchester.ac.uk/api/datastream?publicationPid=uk-ac-manscw: 170650\&datastreamId=FULL-TEXT.PDF (accessed 28 November 2013).

Stone, V. and Tuffin, R. (2000), Attitudes of people from minority ethnic communities towards a career in the police service. Home Office, Policing and Reducing Crime Unit, Research, Development and Statistics Directorate.

Taylor, Lord W. (2005), Review of Police Disciplinary Arrangements Report. Home Office.

Tyler, T. R. (1988), 'What is Procedural Justice? Criteria Used by Citizens to Assess the Fairness of Legal Procedures', Law \& Society Review, 22/1: 103-135.

Tyler, T. R., Callahan, P. E., and Frost, J. (2007), 'Armed, and dangerous (?): Motivating rule adherence among agents of social control', Law \& Society Review, 41/2: 457-492.

Waddington, P. A. J., Stenson, K. and Don, D. (2004), 'In Proportion: Race, and Police Stop and Search', British Journal of Criminology, 44/6: 889-914.

Ward, D. (2003), 'Police officer calls in watchdog to look at race leniency claim', The Guardian, 15 November 2003.

Waters, I. and Brown, K. (2000), 'Police Complaints and the Complainant's Experience', British Journal of Criminology, 40/4: 617-638.

Waters, I., Hardy, N., Delgado, D. and Dahlmann, S. (2007), 'Ethnic minorities and the challenge of police recruitment; The Police Journal, 80/3: 191-216. 